\title{
ИНФОРМАЦИОННЫЙ КАПИТАЛ В СОСТАВЕ ИНТЕЛЛЕКТУАЛЬНОГО КАПИТАЛА ПРЕДПРИЯТИЯ *
}

\author{
(C) 2021 Дмитриев Николай Дмитриевич \\ аспирант, Высшая инженерно-экономическая школа \\ Санкт-Петербургский политехнический университет Петра Великого, Россия, Санкт-Петербург \\ E-mail:dmitriev_nd@spbstu.ru \\ (C) 2021 Зайцев Андрей Александрович \\ доктор экономических наук, профессор \\ Высшая инженерно-экономическая школа \\ Санкт-Петербургский политехнический университет Петра Великого, Россия, Санкт-Петербург \\ E-mail: andrey_z7@mail.ru
}

Трансформация экономического пространства приводит к повышению значимости нематериального компонента в достижении стратегической эффективности. В рыночной среде ключевым ресурсом становится интеллектуальный капитал, активно изучаемый на протяжении последних десятилетий. В то же время вопросы в области интеллектуального капитала непрерывно совершенствуются под воздействием неоднозначной динамики окружающей среды, в частности процессов цифровизации. В настоящей статье предлагается рассмотреть категорию информационного капитала, который в условиях становления экономики знаний становится детерминирующим элементом поступающего развития в экономике и обществе. В результате было определено место информационного капитала в составе интеллектуального капитала.

Ключевые слова: интеллектуальный капитал, информационная среда, информационный капитал, инновационное развитие, цифровая среда, новая экономика, интеллектуальная трансформация, экономика знаний.

\section{Введение}

Современная динамика рыночной конъюнктуры обусловлена переходом к интеллектуальному хозяйствованию. Нематериальные компоненты на текущий момент уже стали доминантами в достижении стратегической эффективности экономических субъектов и определили траектории будущего развития общества. Цифровая среда проникает во все сферы человеческой деятельности и приводит к структурным перестройкам в производственнохозяйственных системах. Последствием данных процессов становится массовая интеграция людей и компаний в цифровую среду, которая характеризуется общей доступностью информации и высокой скоростью ее диффузии (распространения).

Целью настоящей статьи является рассмотрение категории информационного капитала, являющегося детерминирующим элементом поступающего развития в современных экономических и общественных отношениях. Для этого предлагается определить место информа- ционного капитала в составе интеллектуального капитала предприятия. Проведение авторского анализа основывается на материалах, подробно изложенных в исследовании [1].

\section{Основная часть}

Рыночная среда постоянно трансформируется, и для максимизации эффективности от задействования классических факторов производства требуется приложить определенные знания. Еще в трудах П.Друкера [2] говорится, что «знания» как фактор производства проходят три качественных этапа: использование знаний в производственном процессе, использование знаний в трудовой и организационной деятельности, формирование на основе имеющихся знаний новых видов знаний (воспроизводство). Эти этапы стали основой формирования интеллектуального капитала, а именно третий этап позволяет говорить о возрастающей значимости информации в процессах генерации знаний [3].

На протяжении последних десятилетий интеллектуальный капитал активно изучается и давно закрепился как ключевой ресурс

* Исследование выполнено при финансовой поддержке РФФИ в рамках научного проекта № 20-310-90033. 
социально-экономического развития. Однако данная категория остается недостаточно проработанной в научно-практической среде и непрерывно совершенствуется под воздействием неоднозначной динамики окружающей среды, в частности процессов цифровизации [1]. В связи с этим повышается актуальность изучения новообразованных элементов интеллектуального капитала.

С экономической точки зрения наибольшую значимость имеют аспекты коммерциализации результатов интеллектуальной деятельности и вопросы по разрешению проблем, возникающих в процессе создания и практического использования интеллектуальной собственности. Российская Федерация не является исключением, где формирование комфортной среды в области использования и охраны интеллектуальной собственности имеет важное значение для стратегического развития экономической системы страны [4].

Тем не менее нельзя акцентировать внимание только на экономическом аспекте интеллектуального капитала. Любой бизнес-субъект в современных условиях стремится не просто занять свое место на рынке, а достичь лидирующих позиций с получением максимальной отдачи, что невозможно осуществить без учета динамики внешней среды и информационного поля. Интенсификация интеллектуальных процессов в хозяйстве и производстве, особенно в отраслях промышленности, определяет наличие возможностей у экономических субъектов и экономики в целом по формированию стратегической конкурентоспособности путем запуска инновационных процессов в отраслях народного хозяйства и на конкретных территориальных единицах [5].

Существующие модели позволяют выявить качественную зависимость между результатами производственно-хозяйственной деятельности и использованием интеллектуального капитала, в том числе акцентируя внимание на его компонентах, к которым относится и информационный капитал [6]. Проведение объективных оценок осложняется неразвитостью концептуальных подходов и их ограниченностью в связи с отсутствием целостного понимания информационного капитала, а также его места в системе интеллектуализации. Тренд на цифровизацию приводит к многоуровневой и комплексной трансформации как информационной среды в целом, так и паттернов потребления и генерации информации, способствуя формированию новых методологических основ для совершенствования структуры информационного компонента в составе интеллектуального капитала. В то же время возникает объективная сложность построения достоверных моделей в связи с необходимостью привлечения аналитических мощностей для проведения масштабных вычислительных операций [7].

В классическомпонимании использованиена практике информационно-интеллектуального капитала рассматривается как создание и распространение интеллектуально-электронных технологий, облегчающих взаимоотношение между различными субъектами. В таких условиях генерируется устойчивая связь знаний и информации, позволяя объяснить многие процессы в функционировании предприятий. Ограниченность сложившихся подходов заключается в рассмотрении исключительно внутренней значимости информационного фактора в производственном управлении, который позволяет производить рациональный сбор, анализ и обработку информации. Данные аспекты учитываются в практике определения высокотехнологичных отраслей при создании систем их перспективного развития и минимизации риск-условий. В частности, появляется возможность разрабатывать систему управления рисками в деятельности предприятия на основе управления бизнес-процессами путем использования математико-статистического набора инструментов анализа, идентификации и оценки рисков [8; 9].

За последние несколько десятилетий произошли серьезные изменения в структуре социально-экономических отношений. В эпоху экономики знаний ценность материальных факторов и традиционных рентных ресурсов для предприятия снижается [10,11]. Основным источником долгосрочного развития становятся нематериальные элементы, в том числе и информация. Рентообразующая составляющая интеллектуального капитала и информационных потоков обусловила создание сверхприбылей во многих отраслях на основе интенсивных подходов хозяйствования, которые не приводят к сокращению общественного благосостояния. В таком контексте справедлив базис, что стремительное распространение результатов научно-технического прогресса, их фундамен- 
тализация и практическое применение позволяют занимать лидерские позиции на рынке, a также обеспечивают стратегическую конкурентоспособность экономических субъектов на всех уровнях управления [12; 13].

Информационный капитал уже стал стратегическим активом цифровой экономики, а без использования информационных потоков невозможно сформировать экономику знаний, основанную на достижениях Индустрии 4.0 и повсеместном распространении знаниеемкого производства [14]. Экспоненциальное усиление влияния цифровых процессов на экономику и общество произошло в связи с распространением пандемии коронавируса, которая спровоцировала вынужденную самоизоляцию и трансформацию множества экономических и социальных процессов в дистанционную форму. Пандемия COVID-19 всего за несколько месяцев смогла «разогнать» информационную среду и практически мгновенно повлияла на все действия игроков рынка. Еще несколько лет назад подобные экстерналии не давали такого глобального эффекта, что свидетельствует о стремительном развитии информационных потоков и их макровлиянии на всех игроков рынка.

Под воздействием динамичной цифровой трансформации, вызванной пандемией COVID-19, информационный капитал приводит к видоизменению производственнохозяйственной деятельности. Предприятия становятся не просто физическими объектами, но и превращаются в динамический элемент информационной среды. Информация становится той доминантой, учет которой способствует выработке защитных механизмов противодействия внешним негативным проявлениям. Таким образом, в сложившейся цифровой среде информационный капитал во многом определяет результативность и устойчивость деятельности предприятия, однако на практике так и не были сформированы объективные подходы к изучению данного явления.

На сегодня инновационная деятельность является важным драйвером научнотехнологического развития. Информационные потоки в свою очередь направлены на получение качественной отдачи от имеющихся корпоративных ресурсов. Именно на основе использования информационно-аналитических инструментов появляется возможность выстраивать эффективные стратегии противодействия макроэкстерналиям, возникающим в экономической и социальной среде [15]. Следует рассматривать материальную и нематериальную составляющие интеллектуального капитала, которые являются различными по своему концептуальному соотношению с категорией интеллектуальным капиталом. В современных условиях информационный капитал становится нематериальной основой поступающего развития предприятий в связи с возможностью создания точек интеллектуального роста экономических субъектов за его пределами [16].

Новые технологии открывают совершенно новые возможности для использования информационных потоков, а человек становится второстепенным элементом в обеспечение хозяйственных процессов. В рамках предприятия к таким технологиям можно отнести искусственный интеллект, системы IT-управления, Blockchain, построение аналитических прогнозов и так далее. Технологии позволяют перенаправить силы трудовых ресурсов на более значимые задачи и убрать отрицательные эффекты человеческого фактора [17]. В свою очередь, находясь в информационной среде, предприятие в состоянии генерировать информационные импульсы уже за пределами субъекта, ключевой целью которых является формирование у потребителей устойчивого восприятия данного предприятия, что в дальнейшем приводит к увеличению спроса на его продукты и услуги. Данные импульсы формируются предприятием и иными агентами внешней среды, а возможность их вариативно интерпретировать позволяет охарактеризовать конкретную информационную среду предприятия и наличие у него информационного капитала [1].

Информационные потоки приводят к формированию общественного мнения, специфических знаний и спроса на различные блага. Следовательно, информационное поле оказывает серьезное влияние на интеллектуальное положение предприятия и эффективность его стратегической деятельности. В научной среде сложилось неоднозначное отношение к информационному капиталу субъекта. Можно выделить следующие подходы к рассмотрению сущности информационного капитала:

1. Информационный капитал - совокупность материальных носителей, информационных систем и других технологий, которыми располагает предприятие. По своей сущности может 
быть как материальным, так и нематериальным. Материальная сторона - компьютерные информационные системы, а нематериальная - не только компьютерные информационные системы, но и продукты человеческого капитала. Данный вид капитала следует рассматривать как внутренний.

2. Информационный капитал - все накапливаемые, возобновляемые и ликвидные информационные ресурсы, способствующие приращению потенциальных или прямых положительных эффектов для предприятия. Является нематериальным и сосредотачивается как внутри предприятия, так и за его пределами. Является абстрактным и практически не подлежит объективной оценке.

3. Информационный капитал - это внешние показатели (за пределами предприятия), которые объясняют связь предприятия с информационной средой. Информация полностью зависит от индивидуумов, находящихся в социуме. Человек - главный потребитель информации и от ее качественных характеристик способен изменять свое мнение о субъекте. Поведение субъектов определяется факторами, которые зачастую неподвластны прямому или косвенному управлению со стороны предприятия. Следовательно, предприятие должно подстраиваться и вырабатывать стратегии своего поведения в зависимости от информационного поля, которое воздействует на социум.

В результате было определено место информационного капитала и его составляющих в составе интеллектуального капитала (рис. 1). [1].

Использование информационных пото- ков в предпринимательской деятельности носит обширный характер. Доступ к информации в эпоху цифровизации имеется практически у любого субъекта. Таким образом, расширяются возможности по использованию проекций информационной среды, в которой функционируют экономические субъекты, что открывает ряд возможностей для моделирования их поведения в условиях изменения динамики информационного поля. Так, проявление шумов в информационной среде, выраженных в форме слухов и мнений, может привести как к повышению рыночной стоимости, так и к ухудшению состояния компании.

Бизнес-среда непрерывно усложняется под воздействием цифровизации. Данные условия приводят к формированию совершенно новых направлений в предпринимательской деятельности, обуславливая требования по внедрению цифровых технологий и использованию информационных ориентиров в производственнохозяйственной деятельности [18]. Природа формирования информационной среды подвергается значительным изменениям вместе с трансформацией общественных отношений. Флуктуации окружающей среды приводят к волатильности информационного капитала предприятий. Данная ситуация позволяет выработать алгоритмы поведения, которые при возникновении похожих условий в будущем позволят усилить адаптацию и гибкость экономического субъекта.

\section{Заключение}

Интеллектуальный капитал изучен достаточно подробно, однако слабо проработаны

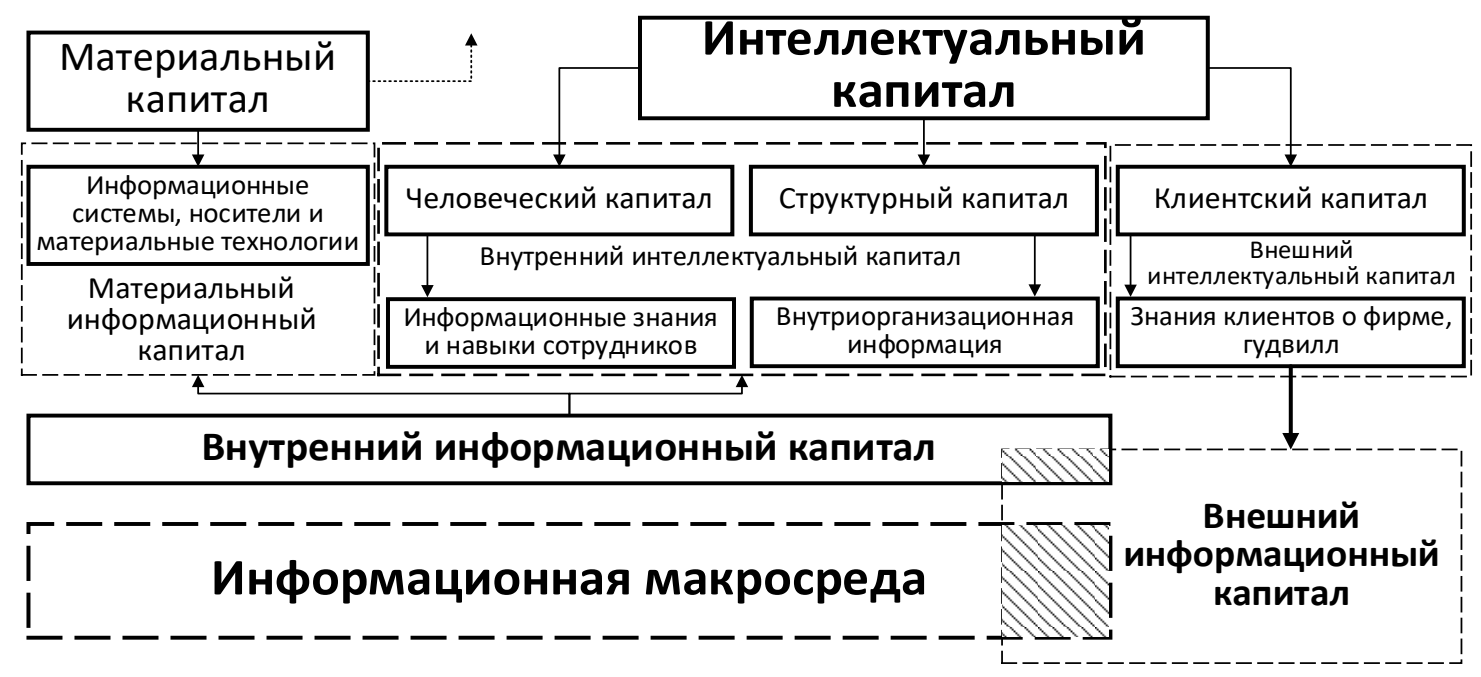

Puc. 1. Информационный капитал в составе интеллектуального капитала 
отдельные его составляющие. В данной статье был рассмотрен информационный капитал, категория которого является неоднозначной. В то же время именно информационный капитал заставляет активизировать как внутренние интеллектуальные процессы на предприятии, так и внешние проявления, происходящие за пределами экономического субъекта. В частности, динамика информационного капитала крайне значима для предприятия, так как она отражает восприятие предприятия его потребителями, конкурентами, контрагентами и иными агента- ми внешней среды, особенно в рамках развития цифровой экономики. В цифровой экономике скорость обмена и доступность информации значительно усилили влияние информационных потоков на экономические результаты компании, обуславливая возможности по созданию интеллектуальной ренты. Таким образом, значимые колебания направленного информационного потока со стороны предприятия могут провоцировать изменения в информационной среде и приводить как к положительным, так и к отрицательным результатам.

\section{Библиографический список}

1. Rodionov D., Zaytsev A., Konnikov E., Dmitriev N., Dubolazova Y. Modeling Changes in the Enterprise Information Capital in the Digital Economy // Journal of Open Innovation: Technology, Market, and Complexity. 2021. № 7. pp. 166.

2. Drucker P. Technology, Management and Society. Routledge, 2012. $184 \mathrm{p}$.

3. Бабскова O.В., Зайцев А. А. Инструментальные методы оценки факторов управления знаниями в регионе // Журнал правовых и экономических исследований. 2019. № 4. С. 147-152.

4. Еленева Ю.Я., Карплюк Ю.А., Андреев В. Н. Инструменты политики в области интеллектуальной собственности как способ повышения конкурентоспособности национальных производителей // Экономика и предпринимательство. 2017. № 8-3. С. 587-590.

5. Zaytsev A., Degtereva V., Dmitriev N. Intellectual and digital industrial enterprise as a way for becoming the industry's leader // Proceedings of the 1st International Scientific Conference on LARDER. 2020. pp. 268-273.

6. Славянов А. С. Подходы к учету интеллектуального капитала в производственной функции // Контроллинг. 2020. № 1. С. 36-41.

7. Родионов Д.Г., Конников Е.А., Конникова О.А. Методология системного анализа информационной среды // Экономические науки. 2021. № 196. С. 160-174.

8. Кочина С.К., Осыченко Е.В. Информационно-интеллектуальный капитал предприятия // Сборники конференций НИЦ Социосфера. 2021. № 1. С. 25-27.

9. Данилочкина Н.Г., Чернер Н.В., Золкин А.Л., Жильцов С.А., Рябкова Г.В. Обоснование необходимости разработки управления рисками на предприятиях высокотехнологичной отрасли // Управленческий учет. 2021. № 8-1. С. 12-18.

10. Зайцев А. А. Рентные проблемы импортозамещения в аграрном секторе экономики РФ // Экономика сельскохозяйственных и перерабатывающих предприятий. 2016. № 5. С. 25-29.

11. Зайцев А.А.Рентный профиль управления устойчивостью аграрных отношений // Известия СанктПетербургского государственного аграрного университета. 2012. № 28. С. 140-144.

12. Дмитриев Н.Д. Эволюционное развитие рентных категорий и формирование концепта «благоприятной ренты» // Управленческий учет. 2021. № 9-1. С. 140-151.

13. Дубаневич Л.Э., Дмитриев Н.Д., Цзэн Я.Инновационное развитие экономики с помощью повышения интеллектуальной ренты // Управленческий учет. 2021. № 7-1. С. 62-74.

14. Чистяков М.С.Цифровая экономика как катализатор постиндустриального информационного развития // Общество, культура, человек в цифровую эпоху. Медиаэкономика, медиаполитика, медиакультура: сборник научных статей. 2020. С. 7-12.

15. Родионов Д.Г., АлферьевД.А.Основные функциональные и технические требования информационноаналитических систем поддержки принятия решений в инновационной деятельности малых промышленных предприятий // Вестник Алтайской академии экономики и права. 2020. № 9-2. С. 294-299.

16. Андреев В.Н., Конончук Т.В. Информационный капитал промышленного предприятия: идентификация категории, проблемы управления в условиях импортозамещения // Вестник МГТУ Станкин. 2015. № 2. С. 130135.

17. Дмитриев Н.Д.Роль цифровой трансформации в информатизации менеджмента качества // Информационно-телекоммуникационные системы и технологии: сборник материалов конференции. 2019. C. 80-81.

18. Сердюкова Л.О., Глушкова Ю. О., Нурулин Р. Н. Бизнес-модели инновационного развития в условиях цифровизации // Инновационная деятельность. 2019. № 4. С. 69-77. 